\title{
Neoliberalismo e reestruturação produtiva: debatendo a flexibilização dos direitos trabalhistas no Brasil
}

\author{
Neoliberalism and productive restructuring: discussing the flexibilisation of labor rights in \\ Brazil
}

\author{
Cleier Marconsin* \\ Valeria Forti** \\ Adauto F. Marconsin ${ }^{* *}$
}

\begin{abstract}
Resumo:
Neste artigo, os autores objetivam mostrar que importantes transformações impostas pela condução neoliberal combinada à reestruturação produtiva marcam a sociedade capitalista brasileira, produzindo graves perdas de direitos dos trabalhadores, dentre eles, os trabalhistas. A metodologia de pesquisa qualitativa utilizada, tendo como norte a perspectiva de totalidade, possibilita trazer reflexões conjuntas dos autores a partir das teses Política Pública de Economia Solidária: uma Política em Construção (2008) e Cerco aos direitos trabalhistas e crise do movimento sindical no Brasil contemporâneo (2009) e da pesquisa "Ética, Direitos, Trabalho e Serviço Social: um estudo no Sistema Penal". A pesquisa documental utilizada na tese "Cerco aos direitos trabalhistas e crise do movimento sindical no Brasil contemporâneo" (2009) oferece o material utilizado na análise dos dados sobre a legislação trabalhista brasileira desde o primeiro mandato de Fernando Henrique Cardoso até o segundo mandato de Lula. No estudo desses dados, constata-se uma linha de continuidade entre os dois governos - Cardoso e Lula -, permitindo concluir que, ao longo desses anos de ingerência do ideário neoliberal, no Brasil, a perspectiva dos governos tem se traduzido na concretização dos interesses do capital financeiro. Dentre vários elementos, a flexibilização dos direitos trabalhistas vem possibilitando esse objetivo.
\end{abstract}

Palavras-Chave: Capitalismo. Neoliberalismo. Reestruturação produtiva. Direitos. Legislação trabalhista.

\begin{abstract}
:
In this article, the authors aim to show that important changes required for conducting combined neoliberal restructuring productive mark the Brazilian
\end{abstract}

\footnotetext{
* Assistente social, formada pela Pontifícia Universidade Católica de Campinas - PUCCAMP (1975). Mestre em serviço social pela Universidade Federal da Paraíba - UFPB - (1997) e doutora, também em serviço social, pela Universidade Federal do Rio de Janeiro - UFRJ - (2009). É docente da Faculdade de Serviço Social da Universidade do Estado do Rio de Janeiro (UERJ) desde 1998. Pesquisadora do Observatório do Trabalho no Brasil da Faculdade de Serviço Social da UERJ. E-mail: cleiermarconsin@gmail.com.

** Doutora em Serviço Social pela UFRJ, Professora Adjunta da Faculdade de Serviço Social da Universidade do Estado do Rio de Janeiro. Integrante do Observatório do Trabalho no Brasil da Faculdade de Serviço Social UERJ E-mail:vlf17@oi.com.br.

** Doutor em Educação pela UNICAMP, Professor das Faculdades Max Planck, Indaiatuba (SP), Pós-Doutorando da Universidade Federal do ABC Paulista.E-mail: adautomarconsin@gmail.com
} 
capitalist society, producing serious loss of workers' rights, among them the labor. The qualitative research methodology used, having as north the perspective of totality, has enabled us reflections of the joint authors of the theses from "Public Policy for the Solidarity Economy: A Policy in Construction" (2008) and "Siege of labor rights and the crisis of the movement union in contemporary Brazil "(2009) and research" Ethics, Rights, Labour and Social Work: A Study in Penal System. "The documentary research used in the thesis" "Siege of labor rights and the crisis of the union movement in contemporary Brazil" (2009) provides the material used in the analysis of data on the Brazilian labor legislation since the first term until Cardoso's second term Lula. In the study of these data, there is a line of continuity between the two governments - Cardoso and Lula - fair to conclude that, over the years of neoliberal interference in Brazil, the prospect of governments has been translated into the realization of interests financial capital. Among various elements, the flexibility of labor rights has enabled this goal.

Keywords: Capitalism. Neoliberalism. Productive Restructuring. Rights. Labor Legislation.

\section{Introdução}

Este texto resulta de reflexões conjuntas dos autores a partir dos resultados dos seus estudos, ${ }^{1}$ trazendo o debate da articulação entre o neoliberalismo e a reestruturação produtiva. Tendo em vista o espaço reduzido de um artigo, que não nos permite penetrar em toda a complexidade do tema, o artigo centra-se na questão da flexibilização dos direitos trabalhistas, no Brasil, nas últimas décadas, com a intenção de contribuir, sem a pretensão de esgotar seu debate, para o entendimento da forma como o fenômeno se apresenta e se desenvolve historicamente. A abordagem teórico-metodológica adotada, por ser operada a partir da perspectiva da tradição marxista, busca conceber o fenômeno imerso numa totalidade concreta - categoria constitutiva da realidade que se articula totalizadora e totalizante - carregada de determinações e contradições postas por processos históricos dinamizados pelo protagonismo das classes sociais. Assim, a discussão parte da relação entre a economia e a política, ou seja, busca entender os fenômenos pelas modalidades por meio das quais a sociedade produz as condições materiais de sua existência, mas também pelas suas implicações políticas, sociais e ídeoculturais.

\footnotetext{
${ }^{1}$ Esses estudos referem-se às teses Política Pública de Economia Solidária: uma Política em Construção (2008) e Cerco aos direitos trabalhistas e crise do movimento sindical no Brasil contemporâneo (2009), e à pesquisa "Ética, Direitos, Trabalho e Serviço Social: Um estudo no Sistema Penal” (ainda em andamento).
} 
Nessa perspectiva, os autores partem da compreensão de que a onda longa recessiva, iniciada na transição da década de 1960 para os anos 1970, engendrou um novo padrão de acumulação do capital, provocando transformações que atingem a totalidade da vida em sociedade. O novo padrão de acumulação, como explicitam Netto e Braz (2007, p. 212), objetiva "reverter a queda da taxa de lucro e criar condições renovadas para a exploração da força de trabalho". No processo em curso, mundialmente, e no Brasil, em particular, efetivaram-se diferentes ações assentadas no ideário neoliberal, combinadas à reestruturação produtiva, viabilizando que diferentes recursos fossem postos em andamento visando à desregulamentação de atividades do capital, bem como de mecanismos socioeconômicos importantes à mobilidade e/ou centralidade do capital financeiro.

\section{Neoliberalismo e reestruturação produtiva: no centro, a flexibilização dos direitos trabalhistas}

Para Netto (2001, p. 77-78), o neoliberalismo traz uma "argumentação teórica que restaura o mercado como instância mediadora societal elementar e insuperável". Esse conceito, para o autor, embasa a "tese da indivisibilidade da liberdade", preconizando que é a "liberdade econômica", fundada no "mercado livre", que possibilita as liberdades, tanto civil quanto política. Nessa concepção, sem "mercado livre" não há forma alguma de liberdade, então, continuando a discussão posta por Netto (2001, p. 79), a funcionalidade do neoliberalismo "abre-se à fundação de um projeto societário global, investindo sobre a estrutura social e a ordem político-institucional". O pressuposto é que o indivíduo deva ser capaz de satisfazer as suas carências e desejos, sem qualquer planificação externa, qualquer controle social definido por instância estatal. Oliveira (1995, apud FORTI, 2009, p. 80) mostra que o neoliberalismo reedita a tese da "supremacia do mercado", ou seja, trata-se de uma instituição perfeita para solucionar o problema econômico nas sociedades modernas, o que falta é “implantá-lo em termos totais", exercendo até função epistêmica. Forti (2010, p. 11) apresenta aportes importantes sobre a concepção neoliberal, que entende ser o desrespeito à liberdade do mercado, ao laissez-faire e à lógica individualista o motivo dos problemas das sociedades modernas. Ainda para a autora, não é pertinente, para esse pensamento, a interferência 
consciente nos assuntos sociais já que as questões das sociedades atuais têm na implantação total do mercado a sua solução. Dessa maneira, não cabe o planejamento socioeconômico porque é mediante a lógica impessoal do mercado - "a sua mão invisível" - que se torna possível a submissão de todos aos padrões gerais.

O reforço desse pensamento em termos mundiais se dá como parte das soluções postas pelo capital para superação de sua crise, para a continuidade da acumulação capitalista. Carrega, como aponta com Netto (2001, p. 77-78), uma proposição política que repõe "o Estado mínimo como única alternativa e forma para a democracia". Nesse caso, ainda concordando com Netto (2001, p. 79-80), o mercado institui o espaço para o Estado atuar, sendo suas únicas funções conforme as "últimas formulações de Hayek": organizar estrutura para o mercado e só criar serviços que o mercado não possa, efetivamente, prover. As regulamentações políticas do mercado são rechaçadas, preconizando um Estado absenteísta.

Mas, vale ressaltar que se trata de um Estado absenteísta no que se refere à garantia de direitos, mas um Estado forte quando se trata de retirar, flexibilizar, precarizar direitos (apresentados como privilégios), desmontar políticas sociais (mostradas como dispendiosas) e criminalizar movimentos sociais e populares que se colocam contrários à continuidade dessa lógica. No que se refere à movimentação governamental - em termos nacionais e internacionais - para viabilizar os negócios da burguesia, a intervenção é naturalizada e tratada como negócios do Estado, do país, de interesse geral (MARCONSIN, 2009). Ou seja, a burguesia não pretende uma total desregulamentação dos mecanismos reguladores da economia, mantendo como imprescindível a presença do Estado para a defesa de seus interesses. Por mais que, no discurso, se apregoe a liberdade de mercado, com a condução neoliberal dos negócios, essa liberdade é circunscrita às necessidades da acumulação capitalista. O que a burguesia preconiza, realmente, conforme Netto (2001, p. 81), é "o estreitamento das instituições democráticas", como "situação ótima" para seus negócios, em face à crise.

Há, então, uma perfeita funcionalidade do pensamento neoliberal ao novo padrão de acumulação capitalista e, por isso, trata-se da diretriz ideológica da grande burguesia. Ainda concordando com Netto (2001, p. 81), a burguesia entende que a proposta do 
"Estado mínimo" pode permitir "o que foi bloqueado pelo desenvolvimento da democracia política, o Estado máximo para o capital" (NETTO, 2001, p. 81).

O neoliberalismo teve início nos países capitalistas centrais por meio de Margareth Thatcher - Primeira Ministra da Inglaterra a partir de 1979 - e de Ronald Reagan Presidente dos Estados Unidos, desde 1980. Se esse ideário se espalhou inicialmente nos países capitalistas centrais, posteriormente, por meio de governos de diferente partidos, inclusive os sociais-democratas - contra os quais se insurgira inicialmente -, atingiu o conjunto das sociedades, em âmbito mundial.

Além de ser um pensamento que avança mundialmente, sua hegemonia nos vários países provoca transformações que atingem a totalidade da vida em sociedade. No âmbito do trabalho, por exemplo, imbricado à reestruturação produtiva, provocou e tem produzido, ainda, transformações profundas.

Hoje vivemos o processo denominado de reestruturação produtiva, mas é importante frisar que o capitalismo reestrutura a produção desde a sua implantação, seja com novas tecnologias, seja organizando novos processos de trabalho, desenvolvendo novos produtos, diferentes padrões de consumo etc. A implantação do binômio fordistataylorista foi um desses momentos, resultado e, ao mesmo tempo, produtor de transformações econômicas e ídeo-políticas fundamentais no mundo da produção e na vida social em geral. Ou seja, as modificações na produção se dão permanentemente, não são isoladas, não se encerram em si próprias.

A atual reestruturação produtiva ocorre com o esgotamento do padrão fordistataylorista - consolidado como acumulação rígida - sendo a base, segundo Harvey (1993, p. 140), do processo de "acumulação flexível". Acumulação flexível que, para o autor, refere-se às inovações tecnológicas, inovações de gerenciamento da produção e do trabalho, que objetivam atender a mercados consumidores diferenciados, por meio de uma real flexibilização da produção e da demanda. Funda-se na flexibilização de processos de trabalho, de produtos e de padrões de consumo (HARVEY, 1993). ${ }^{2}$

Como existe uma inteira relação entre a economia e a política, a flexibilização da legislação trabalhista é conformada nesse processo, ganhando centralidade na sociedade do capital. Nessa relação entre a economia e a política é que entendemos que a causa

\footnotetext{
${ }^{2}$ Para aprofundar os conceitos e as características da acumulação flexível ver Harvey (1993).
} 
primária, então, não se localiza na reestruturação produtiva propriamente dita, mas em sua relação com o neoliberalismo, já que o capitalismo reestrutura-se desde sua gênese. A reestruturação fordista-taylorista, por exemplo, sendo o keynesianismo a diretriz ideopolítica da burguesia ${ }^{3}$, teve como marca a ampliação de direitos. Não é o que ocorre, hoje, com o neoliberalismo. Quanto a isso, cabe observar:

[...] enquanto no contexto do após-guerra a intervenção estatal foi tida como mediação para se enfrentar as crises do capital, como possibilidade de pelo menos minorar substancialmente seus efeitos, a crítica neoliberal inverte tal lógica. Nesta crítica, a intervenção estatal é a causa da crise e não possibilidade de solução (FORTI, 2009, p. 79).

O ohnismo/toyotismo ${ }^{4}$ foi introduzido como técnica voltada para a redução de custos, um novo padrão de produção alinhado à acumulação flexível, ou seja, compatível com os tempos do ideário neoliberal. No âmbito da produção absorve-se do toyotismo a flexibilização da produção (do aparato produtivo e do processo de trabalho) e nas relações de trabalho almeja-se a domesticação dos organismos sindicais dos trabalhadores, instituindo-se uma severa ofensiva sobre os sindicatos. Vale ressaltar que é consenso entre os estudiosos das questões do trabalho na atualidade, tais como Antunes (2001), Tumolo (2002), Bihr (1999) e outros, que não há um modelo que seja exclusivamente toyotista ou fordista-taylorista. Para Tumolo (2002, p. 36), está ocorrendo um amálgama de modelos que provoca a convivência entre eles, objetivando-se economizar força de trabalho.

Nesse caminho e sob a égide da condução neoliberal, dois processos, no âmbito jurídico, acompanham as modificações trazidas pela reestruturação produtiva: a desregulamentação e a flexibilização das legislações trabalhistas, sendo que os dois processos guardam importantes diferenças entre si.

A desregulamentação implica uma atitude totalmente absenteísta do Estado nas relações de trabalho, objetivando que a "autonomia privada, coletiva ou individual, disponha, sem limitações legais, sobre as condições de trabalho" segundo Leite (1997, p. 43). Já a flexibilização, ainda para a autora, ajusta "a aplicação da norma legal a

\footnotetext{
${ }^{3}$ No contexto sócio-histórico de crise do capital, de revoluções e de duas grandes guerras mundiais.

${ }^{4}$ Ohno: principal engenheiro a elaborar o método utilizado pela Toyota.
} 
peculiaridades regionais, empresariais ou profissionais, ainda que alterando condições contratuais para a consecução dessas metas" e/ou retirando direitos. Nesse sentido:

[...] corresponde a uma fenda no princípio da inderrogabilidade das normas de ordem pública e no da inalterabilidade in pejus das condições contratuais ajustadas em favor do trabalhador, visando a facilitar a implementação de nova tecnologia ou preservar a saúde da empresa e a manutenção de empregos (LEITE, 1997, p. 42).

Para Almeida (2006), a flexibilização é a diminuição ou o afrouxamento, a adaptação e até a eliminação da proteção trabalhista no sentido clássico, mostrada pelos defensores do capital como solução para os investimentos, a competitividade da empresa e o desemprego. Tem sido desenvolvida por medidas legais ou convencionadas, que afrouxam imposições jurídicas nos contratos de trabalho, afetando salários, contratação, jornada de trabalho, demissão, férias e outros direitos, cujo resultante imediato é a precarização do trabalho. Para o autor, o fenômeno ganha três diferentes formas, relacionadas às suas fontes. A primeira ocorre mediante "iniciativa unilateral do Estado (seja do poder executivo ou legislativo), que simplesmente derroga, elimina a lei ou norma protetora - é a "flexibilização heterônoma" (URIARTE, apud ALMEIDA, 2006, p. 1)". A segunda forma ocorre pela "negociação coletiva, ou pacto social", que implica a "vontade coletiva" dos trabalhadores - é a chamada "flexibilização autônoma". No caso, a flexibilização não afeta a lei ou a norma de proteção; estabelece que o acordado na negociação coletiva prevaleça sobre o que está legislado. A terceira forma é uma mistura das duas: a "flexibilização mista". Isso significa um acordo construído pela negociação com representações dos trabalhadores, posteriormente, transformado em lei pelo Estado. Mas, para a própria efetivação da "lei nas situações concretas", muitas vezes são necessárias, também, "negociação e contratação coletiva com os sindicatos" (ALMEIDA, 2006, p. 1).

A flexibilização mista, por exemplo, modelo muito falado nos meios jurídicos brasileiros, segundo Maccalóz (1997, p. 21), foi adotada na Espanha desde janeiro de 1994, com o seguinte conteúdo:

1) revalorização da negociação coletiva, como forma de determinar praticamente todas as condições de trabalho; 
2) desregulamentação dos salários, preservando-se direitos mínimos;

3) cláusulas que permitem a não aplicação das convenções coletivas quando estas possam ser negativas à situação da empresa;

4) total soberania da convenção nova sobre o estipulado nas anteriores;

5) permissão para as empresas de trabalho temporário, antes proibidas.

A perspectiva, ainda segundo Almeida (2006, p. 2), é a individualização das relações de trabalho no limite do possível, politicamente, por meio da justificativa da necessidade de adaptação das empresas às exigências da competitividade e da ocupação de mercado. Assim, podemos observar que o ideal neoliberal é a abolição do conceito fundador do direito do trabalho em vários países. No Brasil, por exemplo, para o autor, esse conceito existe pelo reconhecimento de que as relações de trabalho se dão entre partes desiguais.

[...] o direito do trabalho foi concebido com a finalidade de proteger a parte mais fraca - o trabalhador - contra a parte mais forte - o empregador (obviamente estamos falando aqui em teoria). No fundo, o neoliberalismo defende a eliminação da legislação trabalhista e a sua substituição pelo direito comercial ou civil, em que as duas partes da relação, ou do contrato, são entendidas como partes iguais. Dessa forma a relação empregado/empregador ficaria ao sabor da relação (melhor seria dizer pressão) direta entre empregador e empregado (ALMEIDA, 2006, p. 2).

A desconstrução dos coletivos de trabalhadores, então, torna-se essencial, de acordo com Almeida (2006, p. 2), porque são considerados elementos a aumentar "artificialmente" o custo da força de trabalho, afetando a extração de mais-valia. Aqui, o autor trata dos sindicatos denominados combativos e não do sindicato "como instrumento de controle dos trabalhadores". Para coibir a ação sindical combativa, ao mesmo tempo em que o neoliberalismo defende o "afastamento completo do Estado das relações individuais de trabalho", defende uma forte interferência "do mesmo Estado nas relações coletivas de trabalho".

Temos, assim, a característica fundamental de todas as reformas na área trabalhista, inspiradas no receituário neoliberal: o esforço por afastar o Estado das relações individuais de trabalho por um lado, eliminando e/ou flexibilizando os direitos dos trabalhadores protegidos em lei, e, por outro lado, intensificar a interferência do mesmo Estado nas relações coletivas de trabalho, sempre no sentido de restringir a ação coletiva dos trabalhadores, de punir a greve, e de coagir os sindicatos a se transformarem em instrumentos de controle dos trabalhadores, ao invés de serem um instrumento para a sua luta (ALMEIDA, 2006, p. 2, grifo do autor). 
O crescente desemprego, em nível mundial, é um elemento determinante para o avanço do processo da flexibilização. Grandes parcelas de trabalhadores, ao longo das últimas décadas vêm engrossando o exército industrial de reserva e são jogadas em grave situação de pauperização. Para a Organização Mundial do Trabalho (OIT), no mundo, cerca de 200 milhões de trabalhadores estão desempregados ${ }^{5}$ e um terço é de jovens entre 15 e 24 anos de idade. Dessa maneira, a pressão sobre os trabalhadores empregados é bastante acirrada. Os trabalhadores que estão no mercado formal de trabalho são obrigados, em todos os países, a aceitar acordos que desrespeitam direitos trabalhistas - submetendo-se à flexibilização - mostrando a intensificação, hoje, da exploração da força de trabalho.

A flexibilização dos direitos trabalhistas, imposta, então, pela articulação entre o neoliberalismo e a reestruturação produtiva, é mediada pelas condições sócio-históricas particulares dos países e regiões, alastrando-se tanto em tempos diferentes como de modo diversificado. Do ponto de vista das diferenças temporais, esse processo atingiu os países capitalistas centrais desde a década de 1970, mas aprofundou-se a partir dos anos oitenta. Posteriormente, especialmente na transição da década de 1990, atingiu o Leste Europeu, a Ásia, a África e, dada a sua dimensão mundializada, também atingiu os países da América Latina, como Brasil, Argentina e outros. A exceção, talvez, caiba ao Chile, cujos militares deram início à implantação do neoliberalismo, anteriormente.

No Brasil, a busca de saídas para a crise do capital sob a hegemonia neoliberal ocorreu mais efetivamente a partir da década de 1990. Em fins dos anos 1970, a crise mundial do capital atingiu politicamente a autocracia burguesa, derruindo as bases materiais de sua dominação, potencializando as lutas pela sua finalização. Foi assim que, naquele contexto sócio-histórico, na contracorrente do que ocorria em vários países capitalistas centrais, os direitos trabalhistas, no Brasil, antes de refluírem, avançaram.

\footnotetext{
${ }^{5}$ De 3.330 milhões de trabalhadores, 200 milhões estão desempregados, segundo estudos recentes da OIT. Tendências Mundiales Del Empleo Juvenil - 2012. OIT. Disponível em: <www.oit.org.br>. Acesso em: jun. 2012.
} 


\section{Neoliberalismo no Brasil: os caminhos sinuosos da flexibilização dos direitos}

\section{trabalhistas}

O irromper da crise do capital na transição dos anos 1960 para 1970, no Brasil, levou ao esgotamento do padrão de acumulação desenvolvido pela autocracia burguesa desde o golpe militar de 1964, incidindo em sua dinâmica inteira. Observa-se uma efervescência política e, em especial, a reinserção da classe operária, pelo movimento grevista do $A B C$ paulista, na luta por direitos do trabalho. O movimento grevista potencializou outras lutas já em andamento, como pela Anistia, ${ }^{6}$ contra o alto custo de vida, pela reforma partidária, entre outras, encerrando a década de 1970 com uma relação de forças significativamente diferente de seu início. Na contracorrente do que ocorria no mundo capitalista central, dessa maneira, foram lançadas as bases para a conquista de direitos sociais ao longo da década subsequente, em particular, aqueles inscritos na Constituição Federal de 1988.

A Constituição Federal, aprovada no ano de 1988, embora não tenha provocado transformações profundas, trouxe avanços. Além dos direitos políticos, da Educação (préescolar, fundamental e superior), dos aspectos ambientais, da seguridade social (com novos marcos legais, compreendendo o tripé saúde, previdência e assistência), por exemplo, a Constituição apresentou conquistas também em relação aos direitos trabalhistas. Nesse âmbito ressaltamos:

- seguro-desemprego (embora restrito, pois abrange apenas o desemprego involuntário);

- jornada de 6 horas para regimes de turnos;

- ampliação da licença maternidade para 120 dias;

- licença-paternidade de cinco dias;

- redução da jornada de trabalho para 44 horas semanais;

- adicional de férias de 1/3;

- estabelecimento da hora extra a 50\%.

\footnotetext{
${ }^{6}$ A Campanha pela Anistia iniciou-se em 1976 com o Movimento Feminino pela Anistia. Em 1978, foi criado o Comitê Brasileiro pela Anistia (CBA), no Rio de Janeiro. Em novembro do mesmo ano, realizou-se o I Congresso pela Anistia. A anistia conquistada não foi ampla, geral e irrestrita, mas esse movimento foi fundamental, no processo.
} 
Além disso, obteve-se o direito de greve e de sindicalização do funcionalismo público; liberdade e autonomia sindical e, segundo Antunes (1991, p. 74), "foram estendidos ao campo vários direitos sindicais anteriormente restritos ao mundo urbano".

Contudo, desde a promulgação da Constituição os direitos sociais passaram a ser vistos como problemas pela burguesia, objetivando desobrigar o Estado de seu cumprimento. Apresentados como ameaça à democracia, passaram a ser tratados como obstáculo ao saneamento das finanças públicas, alimentadores do processo inflacionário, desencadeadores do desemprego, expressões de interesses corporativos e outras denominações. Em uma lógica inversa, as possibilidades de solução aparecem como causas das questões, as responsáveis pelas crises.

Foi nesse contexto sócio-histórico que a flexibilização dos direitos trabalhistas começou a ser defendida, no Brasil, segundo Maccalóz (1997, p. 8), antes mesmo do Consenso de Washington por "um grupo de advogados patronais, nos Congressos de Direitos do Trabalho [...]".

\begin{abstract}
Falavam da "necessidade" de flexibilizar as leis sociais porque eram "velhas" e "desatualizadas", impediam a competitividade dos produtos brasileiros no exterior, oneravam sobremaneira o empresariado nacional, impediam a ampliação dos mercados de trabalho, geravam o desemprego, não estavam adequadas à modernidade, bloqueavam o desenvolvimento, agrediam a liberdade das partes no contrato de trabalho, anulavam o papel dos sindicatos, afastavam a livre negociação, enfim, a legislação social (sob esta expressão compreende-se as leis trabalhistas e previdenciárias na sua maior abrangência) passou a ser a causa de todos os males; sem ela, com a flexibilização, tudo seria possível, viável, um mundo risonho e sem problemas ao alcance das mãos (MACCALÓZ, 1997, p. 8).
\end{abstract}

Assim, já no governo Sarney - PMDB - (1985-1990), a busca por flexibilizar os direitos impressos na Constituição Federal estava presente, embora nenhuma lei trabalhista tenha sido aprovada ou alterada nesse sentido. Em 1989, fechando a longa década, essa perspectiva avança com a posse de Collor de Mello, que venceu as eleições em segundo turno depois de enfrentar a candidatura de Luis Inácio Lula da Silva, do PT.

O governo Color de Mello - PRN - (1990-1992) encontrou condições econômicas e sociopolíticas para implantar o neoliberalismo reforçadas, como mostra Behring $(2003, p$. 
147-150), pelo "Consenso de Washington, com seu receituário de medidas de ajuste". Após seu impeachment, em 1992, no governo do vice, Itamar Franco - PRN - (1992-1994), foi aprovada uma única, mas significativa, lei em termos de flexibilização trabalhista, a Lei $n^{0}$ 8.949, que regulamentou as cooperativas, acrescentando parágrafo único ao art. 442 da CLT, o qual estabelece a inexistência de vínculo empregatício entre a sociedade cooperativa e seus cooperados, entre estes e a empresa tomadora de serviços. Foi lei significativa porque, com a imposição do neoliberalismo, pelo governo Cardoso, possibilitou avanços da terceirização, no Brasil, com a formação de cooperativas de profissionais diversos e a contratação delas pelos hospitais públicos, por exemplo.

\section{O governo Cardoso e a intenção de "enterrar a Era Vargas"}

No governo Cardoso - PSDB - (1995-2002), o projeto neoliberal incidiu em todas as dimensões da sociedade brasileira. Esse governo, em seu primeiro mandato (1995-1998), viabilizou a privatização das estatais, efetivou no Estado o chamado Plano Diretor da Reforma do Estado - realizado pelo Ministério da Administração e da Reforma do Estado (MARE) - , o que impactou sobremaneira as políticas e os direitos sociais. No âmbito dos direitos trabalhistas, a estratégia de ação governamental voltou-se para a flexibilização da legislação, processo imbricado à reestruturação produtiva, trazida pelas exigências do novo padrão de acumulação capitalista.

A flexibilização ganhou ênfase como justificativa para a superação do desemprego. Segundo Giannotti (2007, p. 288), a intenção de Fernando Henrique Cardoso era "enterrar a Era Vargas, ou seja, [...] flexibilizar as leis trabalhistas, 'engessadas' pela CLT" (Consolidação das Leis Trabalhistas). Conforme Maccalóz (1997, p. 6), o Ministério do Trabalho organizou, nesse período, uma equipe para "estudar os pontos polêmicos da

\footnotetext{
${ }^{7}$ O Consenso de Washington, segundo Fiori (1996, p. 1-2), é "uma expressão acadêmica [...] cunhada por um economista, o sr. John Williamson, um economista menor, sem grande expressão". O autor o define como um receituário formulado em um seminário, em 1989, promovido por instituições financeiras baseadas em Washington - FMI, Banco Mundial - e pelo Departamento do Tesouro dos Estados Unidos, fundamentado no texto do economista acima citado - do International Institute for Economy. Fiori (1996, p.1-2) aponta, também, que o "Consenso de Washington diz respeito à visão norte-americana sobre a condução da política econômica, sobretudo nos países periféricos, no mundo inteiro, mas, obviamente, de forma muito mais direta para os países da América Latina que, naquele momento, eram os países mais individados, situados embaixo da zona de hegemonia, de supremacia norte-americana". Passa a ser imposto como política oficial desde 1990, para promover o ajustamento macroeconômico desses países, frente à crise mundial do capital (FIORI, 1996, p. 1-2). Já Behring (2003) fala da participação de Bresser Pereira, futuro ministro do governo Cardoso nesse seminário do Consenso de Washington (BEHRING, 2003, p. 148).
} 
CLT, de modo a promover mudanças nas relações trabalhistas [...]", voltadas para dar primazia ao acordado em detrimento do legislado. Nesse caminho, o Ministério do Trabalho passou a proibir, desde setembro de 1995, que fiscais multassem empresas envolvidas em acordos quando constatassem incompatibilidade entre as cláusulas contidas neles e a legislação.

Em março de 1996, o Ministro do Trabalho, ainda segundo Maccalóz (1997, p. 5), encaminhou ao congresso um Projeto de Lei (PL) elaborado por juristas da Federação das Indústrias do estado de São Paulo (FIESP), retirado por ser impopular, o que não impediu que outras iniciativas fossem encaminhadas. Em seu segundo mandato (1999-2002), além de dar continuidade à reforma da previdência, Cardoso encaminhou e aprovou mudanças importantes na CLT. Assim, durante os dois mandatos, medidas diversificadas que flexibilizaram os direitos trabalhistas foram instituídas, como apresentadas no quadro 1 , a seguir:

Quadro 1 - Legislação trabalhista flexibilizada durante os dois mandatos do governo Cardoso

\begin{tabular}{|c|c|}
\hline Ano & Leis, Emendas Constitucionais e Legislação Inferior \\
\hline 1995 & $\begin{array}{l}\text { 1) Medida Provisória } 1053 \text { (MP):instituiu a desindexação salarial; } \\
\text { 2) Portaria № } 865 \text { : estabeleceu no art.10, "que as convenções e acordos coletivos de trabalho, bem como seus } \\
\text { respectivos aditamentos, nos termos dos arts. } 614 \text { e } 615 \text { da Consolidação das Leis do Trabalho, serão recebidos } \\
\text { pelo Ministério do Trabalho, através de suas unidades competentes, para fins exclusivamente de depósito, } \\
\text { vedada a apreciação do mérito e dispensada sua publicação no Diário Oficial" e em seu Art.4o, prevê que "a } \\
\text { incompatibilidade entre as cláusulas referentes às condições de trabalho pactuadas em convenção ou acordo } \\
\text { coletivo e a legislação ensejará apenas a comunicação do fato à chefia imediata, que o submeterá à } \\
\text { consideração da autoridade regional". }\end{array}$ \\
\hline 1996 & $\begin{array}{l}\text { Denúncia da Convenção } 158 \text { da OIT. Em janeiro de 1996, o governo solicitou a ratificação dessa convenção - a } \\
\text { qual institui que o empresariado deve justificar, de forma escrita e não apenas oral, as razões das demissões de } \\
\text { trabalhadores. Mas em novembro do mesmo ano entrou com denúncia, ou seja, desistiu da integração dessa } \\
\text { norma à legislação trabalhista. }\end{array}$ \\
\hline 1997 & $\begin{array}{l}\text { 1) MP 1539-34: instituiu trabalho aos sábados e domingos no comércio varejista; } \\
\text { 2) MP 1906: desvinculou a correção do salário mínimo de qualquer índice de reposição da inflação. }\end{array}$ \\
\hline 1998 & $\begin{array}{l}\text { 1) Lei 9601: instituiu o contrato temporário, permitindo que as empresas contratem trabalhadores por } 12 \\
\text { meses, prorrogável por igual período. As empresas podem reduzir a contribuição do Fundo de Garantia de } \\
\text { Tempo de Serviço - FGTS de } 8 \% \text { para } 2 \% \text {. Ao terminar o contrato, a demissão dos trabalhadores pode se dar } \\
\text { sem que a empresa tenha de pagar a multa de } 40 \% \text {. Na mesma lei regulamentou o banco de horas, ampliando o } \\
\text { prazo de compensação de horas extras para até } 120 \text { dias, modificando o artigo } 59 \text { da CLT; } \\
\text { 2) Emenda Constitucional } n^{0} 20 \text { (EC): reformou a previdência social. Essa emenda introduziu importantes } \\
\text { modificações nos Regimes Próprios de Previdência Social (os RPPS's) dos trabalhadores públicos e no do setor } \\
\text { privado - o Regime Geral da Previdência Social (RGPS). Em especial, adotou como critério principal o tempo de } \\
\text { contribuição para a previdência social em substituição ao tempo de serviço, conjugado ou não com idade } \\
\text { mínima. Também aos dois regimes, a EC estabeleceu a necessidade de equilíbrio financeiro e atuarial para sua } \\
\text { concretização. Limitou a concessão de aposentadorias especiais, fixando-a apenas a professores de ensino } \\
\text { fundamental e médio e aos trabalhadores em atividades prejudiciais à saúde ou à integridade física, extinguiu a } \\
\text { aposentadoria proporcional por tempo de serviço. Estabeleceu como limite máximo para aposentadoria do } \\
\text { setor privado o valor nominal de R\$ } 1.200,00 \text {, prevendo reajuste para preservar seu valor real, mas } \\
\text { desvinculado do salário mínimo, estabeleceu redutor de idade para ambos os regimes e dispôs sobre os regimes } \\
\text { de previdência privados, de natureza complementar e facultativo. } \\
\text { 3) MP } 1709: \text { instituiu o trabalho em regime de tempo parcial, alterando a CLT, dispondo que esse tempo parcial } \\
\text { não exceda a } 25 \text { horas semanais e a remuneração seja de acordo com a jornada. Na mesma MP amplia o prazo } \\
\text { de compensação das horas extras (do banco de horas) de até } 120 \text { dias para } 12 \text { meses, ou seja, um ano; } \\
\text { 4) EC n }{ }^{0} \text { 20: modificou o parágrafo VI do Art. } 7^{0} \text { da Constituição que trata da irredutibilidade do salário dos } \\
\text { trabalhadores urbanos e rurais, flexibilizando com o acréscimo da frase: salvo o disposto em convenção ou }\end{array}$ \\
\hline
\end{tabular}




\begin{tabular}{|c|c|}
\hline & $\begin{array}{l}\text { acordo coletivo. Na mesma EC, modificou o inciso XII que trata do salário-família. De para os dependentes dos } \\
\text { trabalhadores ficou dependente do trabalhador de baixa renda nos termos da lei; } \\
\text { 5) Portaria № 207: dispôs sobre o contrato de trabalho por prazo determinado, aprovado na lei } 9601 \text { e } \\
\text { estabeleceu procedimentos relativos ao depósito do referido contrato e sua fiscalização. }\end{array}$ \\
\hline 1999 & $\begin{array}{l}\text { Decreto } 3265 \text { alterou o Regulamento da Previdência Social, introduzindo o "fator previdenciário" para o cálculo } \\
\text { da aposentadoria do RGPS. }\end{array}$ \\
\hline 2000 & $\begin{array}{l}\text { 1) Lei 8959: criou as Comissões Prévias: órgãos paritários de natureza jurídica, formados por pessoas sem } \\
\text { vínculo com a Justiça do Trabalho, tendo por objetivo a solução de conflitos na Justiça do Trabalho, qualquer } \\
\text { que seja sua natureza; } \\
\text { 2) MP 1982-77: regulou a participação dos trabalhadores nos lucros ou resultados da empresa como } \\
\text { instrumento de integração entre o capital e o trabalho e como incentivo à produtividade, nos termos do art. } 7^{\circ} \text {, } \\
\text { inciso XI da Constituição, para os efeitos do disposto no parágrafo único do art. } 62 \text { da Constituição Federal, } \\
\text { estabelecendo no art. } 2^{\circ} \text { que essa participação é objeto de negociação entre a empresa e seus empregados, } \\
\text { mediante procedimentos escolhidos pelas partes de comum acordo. } \\
\text { 3) EC } n^{0} 28 \text { : deu nova redação ao inciso XXIX do art. } 7^{\circ} \text { e revogou o art. } 233 \text { da Constituição Federal, realizando a } \\
\text { redução da prescrição de ação quanto aos créditos resultantes das relações de trabalho rural de } 5 \text { para } 2 \text { anos. }\end{array}$ \\
\hline 2001 & $\begin{array}{l}\text { 1) MP 2164-41: modificou a MP de número } 1709 \text { de } 1998 \text {, atingindo o Artigo 58-A da CLT sobre trabalho em } \\
\text { regime de tempo parcial - } 25 \text { horas semanais. Dispôs que as férias, para o trabalho em regime de tempo } \\
\text { parcial, são de } 18 \text { a } 8 \text { dias, dependendo do número de horas da jornada e não do número de meses } \\
\text { trabalhados. } \\
\text { 2) MP } 2164-41 \text { modificou a MP } 1726 \text { - a qual criou a figura da suspensão temporária do contrato de trabalho } \\
\text { - estipulando que o contrato de trabalho poderá ser suspenso por um período de dois a cinco meses para } \\
\text { participação do empregado em curso ou programa de qualificação profissional oferecido pelo empregador, com } \\
\text { duração equivalente à suspensão contratual, estabelecido em convenção ou acordo coletivo de trabalho e com } \\
\text { aquiescência formal do empregado. No artigo } 3^{\circ} \text { estabelece que o empregador poderá conceder ao empregado } \\
\text { ajuda compensatória mensal, sem natureza salarial, durante o período de suspensão contratual nos termos do } \\
\text { caput deste artigo, com valor a ser definido em convenção ou acordo coletivo. No artigo } 18 \text { criou o Conselho } \\
\text { Deliberativo do Fundo de Amparo ao Trabalhador (CODEFAT) composto por representantes de trabalhadores, } \\
\text { empregadores e órgãos governamentais e instituiu uma bolsa do FAT para trabalhadores demitidos, com } \\
\text { contrato de trabalho suspenso para a qualificação referida anteriormente; } \\
\text { 3) Lei no } 10.243 \text { : incluiu um parágrafo no art. } 58 \text { da Seção II, que trata da jornada de trabalho. No parágrafo } \\
\text { incluído ficou estabelecido que o "tempo despendido pelo empregado até o local de trabalho e para o seu } \\
\text { retorno, por qualquer meio de transporte, não será computado na jornada de trabalho, salvo quando, tratando- } \\
\text { se de local de difícil acesso ou não servido por transporte público, o empregador fornecer a condução". }\end{array}$ \\
\hline 2002 & $\begin{array}{l}\text { Portaria } n^{0} \text { 329: estabeleceu procedimentos para a instalação e o funcionamento das Comissões de Conciliação } \\
\text { Prévia e Núcleos Intersindicais de Conciliação Trabalhista. }\end{array}$ \\
\hline
\end{tabular}

Fonte: Marconsin (2009).

Vale observar que, em 2001, o governo Cardoso apresentou o PL 5483/01 que propunha modificar o artigo 618 da CLT, permitindo a empregadores e empregados negociações sobre horas extras, repouso semanal, férias e outras. Foi aprovado na Câmara dos Deputados, mas não foi votado no Senado em função de um processo forte de resistência de setores do movimento sindical dirigidos pela CUT, que incluiu uma greve geral.

Isso significa que, nos oito anos de mandato de Cardoso, apesar do refluxo das mobilizações, as lutas desenvolvidas pelo movimento sindical impediram, em alguma medida, a implantação pretendida da flexibilização dos direitos trabalhistas. Esse processo frustrou, por exemplo, a intenção de Cardoso em encerrar a era Vargas, de romper as amarras da CLT, impedindo que o negociado viesse a prevalecer inteiramente sobre o legislado. 
Em 2002, o PT canalizou eleitoralmente a insatisfação de amplos segmentos da população brasileira, elegendo Luis Inácio Lula da Silva.

Flexibilização dos direitos trabalhistas no governo Lula: uma impossibilidade?

Para Sader (2009, p. 89), no governo Lula - PT - (2003-2011) houve mudanças significativas em relação ao de Cardoso, em especial no que se refere à "integração regional em relação aos tratados de livre-comércio e a promoção dos direitos econômicos e sociais dos mais pobres". Behring (2008, p. 160) também considera que houve "avanços possíveis" com uma certa recomposição do quadro de recursos humanos do governo federal, proporcionada pela realização de concursos em várias áreas que se encontravam desprofissionalizadas e, em especial, no âmbito da assistência com a criação do Sistema Único de Assistência Social (SUAS), por exemplo, pelo Ministério de Desenvolvimento Social e Combate à Fome (MDS). O Programa Bolsa-Família (PBF) também trouxe inovações por tratar-se de um programa de transferência de renda que unificou as várias bolsas existentes, sendo financiado com verbas orçamentárias “(parte fiscal e parte da seguridade)", permitindo o acesso de maior número de pessoas. Ao mesmo tempo, tem impactado "a economia dos pequenos municípios e o cotidiano da vida das pessoas, em especial, na área da alimentação" (BEHRING, 2008, p. 169). Algumas outras diferenciações foram possíveis, em nossa opinião, em decorrência da conjuntura econômico-financeira internacional mais favorável. Essas e outras ações, voltadas para o crescimento, possibilitaram, ao governo Lula, uma diferenciação em relação a seu antecessor e, de fato, um índice de crescimento maior.

Todavia, ao longo dos dois mandatos, observa-se a manutenção das "políticas de desregulamentação financeira, de juros elevados e de superávit primário cavalar, que propiciaram a livre circulação e elevada lucratividade do capital financeiro" como aponta Boito Junior (2004, p. 3). Aprofundou a prioridade das exportações, destacando-se os produtos primários como a soja transgênica, por exemplo, com privilégio do agronegócio em detrimento da reforma agrária; não reverteu o encaminhamento das privatizações que dilapidaram o patrimônio público e expandiram a terceirização, prosseguindo os leilões para licenças de exploração privada do petróleo e gás. Além disso, teve como "forte fio de continuidade" com o governo Cardoso, segundo Behring (2008, p. 163), a 
"parca alocação de recursos para a seguridade social", em geral, e a assistência social em particular", ou seja, "a inovação esbarra nos elementos de continuidade". Em relação ao Programa Bolsa-família, também, ao par com inovações manteve continuidades com a condução neoliberal, uma vez que não se constituiu um "direito adquirido a exemplo do Programa de Prestação Continuada (BPC) e da aposentadoria rural" e muitos trabalhadores que trabalham no Programa têm contrato temporário, com direitos flexibilizados, como aponta Behring (2008, p. 169).

Do ponto de vista da legislação trabalhista, observa-se a manutenção da perspectiva de flexibilização, a qual expressou-se, de início, na Emenda Constitucional (EC) $\mathrm{n}^{0} 41,{ }^{8}$ referente à previdência social, encaminhada ao Congresso no primeiro semestre de 2003, no início de seu primeiro mandato (2003-2006), atendendo à Carta Compromisso ao FMI do governo Lula. ${ }^{9}$ A defesa da Emenda Constitucional foi acompanhada de uma ofensiva campanha ideológica, via mídia, que mostrava os trabalhadores do serviço público como privilegiados, a reforma como meio de promoção da justiça social e reversão do déficit da Previdência. A campanha ideológica foi acompanhada por ações repressivas sobre os servidores públicos contrários à Emenda Constitucional em tela, de liberação de verbas aos parlamentares que a aprovaram e de expulsão de parlamentares do PT que votaram contra a Emenda Constitucional (EC) $n^{0} 41$, por parte da direção do partido.

No segundo mandato do governo Lula (2007-2010), a continuidade da defesa da flexibilização da legislação trabalhista foi acompanhada, também, pela Justiça do Trabalho, segundo Guedes (2007, p. 1), "em detrimento do paradigma constitucional".

\footnotetext{
Emerge uma legislação recheada de imperativos de modernização dos conflitos distributivos e de sustento a uma organização produtiva. Chanceladas pela jurisprudência, essas leis acabaram atraindo o direito do trabalho para a órbita de um verdadeiro direito da economia ou da racionalização econômico-social, responsável por uma significativa transformação nas técnicas legislativas do sistema de fontes e da forma de legitimação do direito do trabalho, o que, com propriedade, Massimo D'Antona denominou de oportunismo metodológico.
}

\footnotetext{
${ }^{8}$ Aprovada em dez/2003, modificou artigos da Constituição Federal, dispositivos da Emenda Constitucional no 20 - de 15/12/1998, além de fixar em $R \$ 2.400,00$ o teto para a aposentadoria dos trabalhadores do Regime Geral da Previdência Social (RGPS) (TEIXEIRA, 2006).

${ }^{9}$ CARTA COMPROMISSO AO FMI. Governo Lula. Assinada pelo Ministro da Fazenda e Presidente do Banco Central. 28 de fevereiro de 2003. Disponível em: <http://www.brasil.gov.br>. Acesso em 2003.
} 
Pelo que podemos verificar, a flexibilização dos direitos trabalhistas caminhou agilmente no Brasil em função da aceitação, por parte de uma ponderável parte dos juízes brasileiros, da racionalização socioeconômica.

\begin{abstract}
O pensamento único estendeu-se sobre a ideia de que o desemprego era inexorável e que a única forma de amainar seus efeitos era aceitar a flexibilização [...]. Longe de evitar o desemprego em massa, esse apanágio da razão cínica criou um regime de trabalho precário que não para de crescer, e, dado seu alto poder de instrumentalização das pessoas, favorece a banalização do mal. O psicoterror no trabalho prospera na new economy [...] (GUEDES, 2007, p. 2).
\end{abstract}

Guedes (2007, p. 2) considera também que os avanços do "verbo da flexibilização" na jurisprudência brasileira relacionam-se à insistência de instâncias governamentais na época, o governo Lula - sobre a necessidade de "modernização" da legislação trabalhista e sindical. Os tribunais, neste sentido, desencorajam os chamados "juízes fundamentalistas", que continuam a ter como "fundamento de suas decisões os direitos humanos, com ameaças e punições administrativas em nome da disciplina judiciária". Com isso, os artigos 468 e 619 da CLT encontram-se sob ataque. A combinação destes artigos constitui, ainda segundo Guedes (2007, p. 2), a "espinha dorsal do Direito do Trabalho" e pode ser traduzida "por uma única palavra: proteção", já que reconhece que as relações de trabalho se dão entre partes desiguais, protegendo a parte economicamente mais frágil do contrato. $\mathrm{O}$ artigo 468 proíbe a modificação do contrato que prejudique o trabalhador, ainda que ele tenha consentido. Já o artigo 619 impede a violação do estatuto mínimo. Ou seja, os contratos não podem prevalecer sobre o legislado, mesmo quando há consentimento, quando o primeiro é mais benéfico, não se podendo contratar menos direito do que a lei determina.

O ideal neoliberal para as relações de trabalho, então, seria a extinção dessa espinha dorsal do Direito, como denomina Guedes (2007, p. 2) - conceito fundante dos direitos trabalhistas em países como o Brasil. Com essa eliminação, a legislação trabalhista seria substituída pelo direito comercial ou civil, entendendo as duas partes do contrato como iguais, permanecendo apenas a relação direta (e individual) entre empregador e empregado. 
Assim, podemos dizer que as leis que flexibilizam os direitos trabalhistas, aprovadas durante o governo Cardoso (1994-2002), permaneceram inalteradas, em sua maioria, no governo Lula (2003-2010), aparecendo, hoje, novos mecanismos de flexibilização tanto da legislação quanto de organismos estatais que a regulam. Nesse sentido, foram aprovadas Emendas Constitucionais, Medidas Provisórias e legislação inferior como Portarias e Instruções Normativas, apresentadas no quadro 2, a seguir.

Quadro 2 - Legislação trabalhista flexibilizada durante os dois mandatos do governo Lula

\begin{tabular}{|c|c|}
\hline \multicolumn{2}{|r|}{ Leis, Emendas Constitucionais e Legislação Inferior } \\
\hline Ano: 2003 & $\begin{array}{l}\text { Emenda Constitucional no } \mathbf{4 1} \text {, de 19/12/2003. Modifica os artigos } 37,40,42,48,96,149 \text { e } 201 \text { da } \\
C F / 88 \text {, revoga o inciso IX do } \S 3 \text { do art. } 142 \text { da CF/88 e dispositivos da Emenda Constitucional no 20, } \\
\text { de } 15 \text { dezembro de } 1998 \text {, e outras providências. }\end{array}$ \\
\hline Ano: 2004 & $\begin{array}{l}\text { Emenda Constitucional 45. Altera a competência da Justiça do Trabalho (nos parágrafos segundo e } \\
\text { terceiro do Art. 114). } \\
\S 20 \text { : insere a frase "de comum acordo" - ou seja, só haverá interferência da Justiça do trabalho se } \\
\text { as duas partes estiverem de acordo; } \\
\S 30 \text { : Em caso de greve em atividade essencial, o Ministério Público do Trabalho tem legitimidade } \\
\text { para ajuizamento de ação coletiva quando não forem assegurados os serviços mínimos à } \\
\text { comunidade ou assim exigir o interesse público ou a defesa da ordem jurídica. }\end{array}$ \\
\hline Ano: 2005 & $\begin{array}{l}\text { Lei 11.101, de } 9 \text { de fevereiro de } 2005 \text {. Lei de Falências. Regula a recuperação judicial, a extrajudicial } \\
\text { e a falência do empresário e da sociedade empresária. Dentre os vários artigos e parágrafos, no que } \\
\text { se refere aos diretos trabalhistas, a lei prevê: } \\
\text { Art. } 50 \text {. VIII: redução salarial, compensação de horários e redução da jornada, mediante acordo ou } \\
\text { convenção coletiva; } \\
\text { Art. 54: prazo de até } 1 \text { (um) ano para pagamento dos créditos derivados da legislação do trabalho ou } \\
\text { decorrentes de acidentes de trabalho vencidos até a data do pedido de recuperação judicial. } \\
\S \text { único: prazo de até } 30 \text { (trinta) dias para o pagamento, até o limite de } 5 \text { (cinco) salários-mínimos } \\
\text { por trabalhador, dos créditos de natureza estritamente salarial vencidos nos } 3 \text { (três) meses } \\
\text { anteriores ao pedido de recuperação judicial; } \\
\text { Art. 83: A classificação dos créditos na falência obedece à seguinte ordem de prioridade: } \\
\text { I: os créditos derivados da legislação do trabalho, limitados a } 150 \text { (cento e cinqüenta) salários- } \\
\text { mínimos por credor, e os decorrentes de acidentes de trabalho; }\end{array}$ \\
\hline Ano: 2006 & $\begin{array}{l}\text { Lei Complementar no 123, de } 14 \text { de dezembro de } 2006 \text { - Lei Geral da Micro e Pequena Empresa } \\
\text { (Super Simples). No artigo 10, reproduz-se o que já existe no Estatuto das Micro e Pequenas } \\
\text { Empresas, mas também traz mudanças. As modificaçães que mais nos interessam, aqui, intitulam-se } \\
\text { DA SIMPLIFICAÇÃO DAS RELAÇÕES DE TRABALHO. } \\
\text { Art. 1 }{ }^{0} \text { : estabelece normas gerais relativas ao tratamento diferenciado e favorecido a ser dispensado } \\
\text { às microempresas e empresas de pequeno porte no âmbito dos Poderes da União, dos Estados, do } \\
\text { Distrito Federal e dos Municípios. } \\
\text { Art. } 51 \text { : As microempresas e as empresas de pequeno porte são dispensadas: I - da afixação de } \\
\text { Quadro de Trabalho em suas dependências; II - da anotação das férias dos empregados nos } \\
\text { respectivos livros ou fichas de registro; III - de empregar e matricular seus aprendizes nos cursos dos } \\
\text { Serviços Nacionais de Aprendizagem; IV - da posse do livro intitulado "Inspeção do Trabalho"; e V- } \\
\text { de comunicar ao Ministério do Trabalho e Emprego a concessão de férias coletivas. } \\
\text { Art. } 55: \text { A fiscalização, no que se refere aos aspectos trabalhista, metrológico, sanitário, ambiental e } \\
\text { de segurança, das microempresas e empresas de pequeno porte deverá ter natureza } \\
\text { prioritariamente orientadora, quando a atividade ou situação, por sua natureza, comportar grau de } \\
\text { risco compatível com esse procedimento. Parágrafo I: Será obervado o critério de dupla visita para } \\
\text { lavratura de autos de infração, salvo quando for constatada infração por falta de registro de } \\
\text { empregado ou anotação da Carteira de Trabalho e Previdência Social - CTPS, ou, ainda, na } \\
\text { ocorrência de reincidência, fraude, resistência ou embaraço à fiscalização. } \\
\text { Art. } 58: \S \text { III: Poderão ser fixados, para as microempresas e empresas de pequeno porte, por meio de } \\
\text { acordo ou convenção coletiva, em caso de transporte fornecido pelo empregador, em local de difícil } \\
\text { acesso ou não servido por transporte público, o tempo médio despendido pelo empregado, bem }\end{array}$ \\
\hline
\end{tabular}




\begin{tabular}{|c|c|}
\hline & $\begin{array}{l}\text { como a forma e a natureza da remuneração." } \\
\text { Art. 75: As microempresas e empresas de pequeno porte deverão ser estimuladas a utilizar os } \\
\text { institutos de conciliação prévia, mediação e arbitragem para solução dos seus conflitos. Parágrafo I: } \\
\text { Serão reconhecidos de pleno direito os acordos celebrados no âmbito das comissões de conciliação } \\
\text { prévia. }\end{array}$ \\
\hline Ano: 2007 & $\begin{array}{l}\text { Instrução normativa no 72, de } \mathbf{5} \text { de dezembro 2007: Refere-se à Lei Geral da Micro e Pequena } \\
\text { Empresa. Orienta os Auditores-Fiscais sobre os procedimentos da fiscalização, para dar às micro e } \\
\text { pequenas empresas tratamento diferenciado estabelecido pela lei. }\end{array}$ \\
\hline Ano: 2007 & $\begin{array}{l}\text { Portaria } \text { n }^{0} \text { 42, de } 28 \text { de março de 2007, do TEM: altera horários de alimentação dos trabalhadores. } \\
\text { Art. } 1^{0} \text { : Institui que o intervalo para repouso ou alimentação de que trata o artigo } 71 \text { da CLT poderá } \\
\text { ser "reduzido por convenção ou acordo coletivo de trabalho, devidamente aprovado em assembleia } \\
\text { geral, desde que os empregados não estejam submetidos a regime de trabalho prorrogado e o } \\
\text { estabelecimento do empregador atenda às exigências concernentes à organização dos refeitórios e } \\
\text { demais normas regulamentadoras de segurança e saúde no trabalho". }\end{array}$ \\
\hline Ano: 2008 & $\begin{array}{l}\text { Lei } \mathrm{n}^{0} \mathbf{1 1 . 7 1 8} \text { de } 20 \text { de junho de } 2008 \text { - muda a Lei no } 5.889 \text {, de } 8 \text { de junho de } 1973 \text {, instituindo o } \\
\text { Contrato de Trabalhador Rural por Pequeno Prazo. Dentre vários artigos, propõe que o produtor } \\
\text { rural poderá realizar contratação de trabalhador rural por pequeno prazo para o exercício de } \\
\text { atividades de natureza temporária, sem necessidade de registro em carteira, utilizando-se de um } \\
\text { contrato - aprovada na Câmara dos Deputados, faltando ser aprovada no Senado. }\end{array}$ \\
\hline
\end{tabular}

Fonte: Marconsin (2009).

Observa-se pela legislação aqui apresentada uma tendência, no governo Lula, de não eliminar leis, mas flexibilizá-las, aprovando, gradualmente, no congresso, itens pontuais da legislação e, ao mesmo tempo, expedindo portarias. Para isso, entendemos, seguindo as análises de Almeida (2006, p. 2) sobre o ideário neoliberal, que o governo empenhou-se na desconstrução dos coletivos de trabalhadores. Ou seja, buscou enfraquecer os sindicatos denominados combativos, fortalecendo aqueles que se colocam "como instrumento de controle dos trabalhadores" porque toda a legislação encaminhada pelo governo Lula foi debatida e acompanhada, senão negociada, com direções das organizações significativas dos trabalhadores, em especial, tendo protagonismo maior a Central Única dos Trabalhadores (CUT). Nesse sentido, caracterizase a flexibilização ocorrida no governo Lula como "mista", de acordo com a caracterização de Almeida (2006, p. 2).

\section{Considerações finais}

A condução neoliberal combinada à reestruturação produtiva trouxe importantes transformações que marcam a sociedade brasileira, em particular, gerando graves perdas de direitos para os trabalhadores. Do ponto de vista da legislação trabalhista, podemos dizer que a intencionalidade dos governos que se sucederam desde os inícios do neoliberalismo até a atualidade foi e tem sido a sua flexibilização. As medidas adotadas voltam-se para flexibilizar a remuneração, a aposentadoria, a jornada de trabalho, as 
relações com os órgãos de regulação como o Ministério do Trabalho, por exemplo. Mas vale ressaltar que o cerco maior, além da aposentadoria, parece ter sido a regulamentação da jornada de trabalho com três mudanças significativas: 1 . jornada parcial; 2. banco de horas e aumento do prazo para sua utilização; 3 . supressão da contagem, na jornada de trabalho, do tempo gasto em transporte até a empresa e no retorno ao domicílio, a não ser quando for local de difícil acesso ou não servido por transporte público e o empregador tiver de fornecer a condução.

Para Leite (1997, p. 31), as mudanças realizadas pelo governo Cardoso mostram uma tendência ao "retrocesso doutrinário", pois se deixa de visar o "Direito do Trabalho fundado e escudado em dispositivos legais", ancorando-se apenas "em normas provenientes de contratos e acordos coletivos ou nos próprios regulamentos das empresas". A intenção foi, de fato, impor o acordado sobre o legislado.

Entendemos que a condução política do governo Cardoso, cujo partido (PSDB) reivindica-se como social-democrata, esteve em total sintonia com as orientações emanadas do Banco Mundial e do FMI - em consonância com as necessidades postas pela acumulação do capital. Para Maccalóz (1997, p. 20-23), a perspectiva hegemônica durante o governo Cardoso foi a de flexibilizar a "utilização da força de trabalho e qualquer modalidade de garantia de emprego", com tendência à "extinção de direitos", caracterizando-se como um "retrocesso jurídico, político, social e democrático", que nos joga em uma situação como a vivida nos períodos iniciais do século XX. O retrocesso ao qual a autora refere-se é parte intrínseca da contrarreforma, como apontam Coutinho (2008) e Behring (2003), também vivida no Brasil com a implantação do neoliberalismo.

As (poucas) reformas conquistadas aqui, em especial ao longo do século $X X$, as quais garantiram um nível mínimo de direitos humanos, compreendidos dentro deles os trabalhistas, sofreram uma desconstrução brutal, um verdadeiro retrocesso, trazendo sérias consequências aos trabalhadores brasileiros. Se, na Europa, como evidencia Mattos (1998, p. 54), o neoliberalismo "atingiu sociedades em que o nível de controle sobre o mercado de trabalho e as conquistas dos trabalhadores haviam avançado muito desde o pós-guerra", em terras brasileiras, a pletora resultante da flexibilização incidiu em um "mercado de trabalho em que inexiste garantia contra a demissão imotivada e em que o seguro desemprego é conquista recente e restrita". Com um detalhe importante: "as 
fórmulas e os discursos já estavam disponíveis em abundância no mercado internacional quando os empresários e políticos brasileiros deles se apropriaram". Adotaram tais discursos para justificar "com grande furor", em especial, a flexibilização dos direitos trabalhistas, mesmo sendo o Brasil uma "sociedade em que as regulações do mercado sempre se fizeram em função dos interesses diretos de frações do capital próximas ao aparelho de Estado" e os direitos dos trabalhadores "sempre foram limitados em sua abrangência", flexíveis e "marcados pelo caráter autoritário do controle estatal sobre as organizações sindicais" (MATTOS, 1998, p. 54).

Com Coelho (2005, p. 422), vimos que o governo Cardoso flexibilizou direitos trabalhistas para "facilitar a imposição de rebaixamentos no valor da força de trabalho" e proceder à superexploração. Para o autor, a flexibilização e "a proliferação das formas precárias de arregimentação da força de trabalho provocaram o rápido aumento da concorrência entre os trabalhadores". Mais que isso, ambas "levaram também ao aprofundamento da diferenciação interna da classe trabalhadora", intensificando a distinção, já histórica, entre os setores que possuem "emprego formal e outros precarizados, entre os vínculos empregatícios duradouros e temporários, entre aqueles que se ocupam em tempo integral e em tempo parcial" (COELHO, 2005, p. 422). Em nosso entendimento, os trabalhadores foram colocados na posição de optar entre perder direitos ou perder o emprego. Embora a produtividade continuasse a crescer, para os trabalhadores era uma situação extremamente grave, pois o emprego decrescera. ${ }^{10}$

Já o governo Lula, apesar de conter alguns aspectos diferenciados do governo Cardoso, não realizou a ruptura esperada, dando continuidade ao ideário neoliberal. Quando colocamos uma lente de aumento na questão da legislação trabalhista - objeto de nosso debate - isso aparece de forma muito clara. Assimilando o ideário neoliberal, o PT, no governo federal, mostrou ter abandonado concepções e posições ideopolíticas defendidas no processo sócio-histórico anterior e manteve a disposição de processar a continuidade da flexibilização dos direitos trabalhistas. Para garantir esse procedimento, buscou intensificar mecanismos eficientes de interferência nas organizações sindicais,

\footnotetext{
${ }^{10}$ Para Mattos (1998, p. 59), o crescimento da produção e da produtividade revela-se diferente ao do emprego. Informa o autor, que os dados "dos fabricantes de veículos e autopeças, sistematizados pelo Dieese, indicam que entre 1991 e 1995 as taxas de crescimento da produção, da produtividade e do emprego foram, respectivamente, de $70 \%, 78 \%$ e $-5 \%$. Ou seja, enquanto a produtividade do trabalho quase dobrou, o emprego foi reduzido".
} 
intentando transformá-las em instrumentos de controle dos trabalhadores, restringindo as lutas de resistência, aprofundando a cisão do movimento sindical, provocando uma crise de grande alcance e longa duração.

No estudo da legislação aprovada durante o governo Lula identificamos que, até o final dos dois mandatos, o governo Lula não logrou flexibilizar os direitos de uma única vez, por meio de uma proposta integral como pretendia quando criou, em 2003, o Fórum Nacional do Trabalho (FNT). A flexibilização se expressou de diferentes formas: parlamentares do PT e da base governista aprovaram leis, mesmo de partidos de oposição e apresentaram PL(s) que flexibilizariam a legislação. O governo aprovou, gradualmente, no congresso, itens pontuais da legislação trabalhista, ao mesmo tempo em que expediu portarias que a flexibilizam.

No processo como um todo, evidencia-se que a concepção de flexibilização do governo Lula foi a "mista", de acordo com tipologia apresentada por Almeida (2006, p. 1), já que os mecanismos de negociação com os sindicatos estiveram presentes para sua concretização. Todavia, os dados estudados mostram que o objetivo não se voltou apenas para flexibilizar a legislação trabalhista, mas também a ação dos órgãos responsáveis pela regulação e fiscalização dos direitos e mais: a flexibilização não situa-se apenas no executivo. Está presente no poder legislativo e judiciário, em total consonância com os interesses do capital.

Observa-se, assim, ao longo dos anos de ingerência do ideário neoliberal, no Brasil, a perspectiva de concretizar os interesses do capital financeiro e das grandes corporações, comandantes contemporâneos do novo padrão de acumulação, cujo conteúdo é a imposição da liberdade de mercado, como se as relações entre trabalhadores e empregadores fossem relações entre iguais, deixando à mão invisível, de que nos fala Adam Smith, a promoção do bem-estar de todos. Também no Brasil, o mercado deve ser livre de restrições de toda ordem para a produtividade e lucratividade. Bonfim (1997, p. 48) ressalta que, hoje, viemos a ressurreição da "metáfora da mão invisível", tão cara aos liberais. Concordando com Chesnais (1996, p. 42), entendemos que no cenário posto pelo ideário neoliberal, as legislações do trabalho conquistadas por lutas sociais e por "ameaças de revolução social voaram pelos ares", sendo que as 
"ideologias neoliberais se impacientam de que ainda restem alguns cacos delas". Esse é o cerne do que vem ocorrendo no Brasil da atualidade.

\section{Referências}

ALMEIDA, J. M. A reforma trabalhista e sindical em preparação pelo governo federal: mais ataques aos direitos dos trabalhadores. São Paulo, 2006. Disponível em:

$<w w w$. conlutas.org.br>. Acesso em: out. 2006.

ANTUNES, R. O Novo Sindicalismo. São Paulo, Ed. Brasil Urgente, 1991.

. Os sentidos do trabalho: Ensaio sobre a afirmação e a negação do

trabalho. 5ª edição, São Paulo, Boitempo, 2001.

BEHRING, E. R. Brasil em contra-reforma: desestruturação do Estado e perda de direitos. São Paulo, Cortez, 2003.

Trabalho e seguridade social: o neoconservadorismo nas políticas sociais. In:

BEHRING, E. R.; ALMEIDA, M. H. T. Trabalho e seguridade social: percursos e dilemas. Rio de Janeiro: UERJ, 2008, p. 152-174.

BHIR, A. Da grande noite à alternativa: o movimento operário inglês em crise: col. mundo do trabalho. 2. ed. São Paulo: Boitempo, 1999.

BOITO JUNIOR, A. A grande ilusão da elite sindical. Gazeta Mercantil, São Paulo, Primeira Página, 13 de Outubro de 2004.

BONFIM, B. C. Globalização, flexibilização e desregulamentação do direito do trabalho. In: MACCALÓz, M. S. et al. Globalização, neoliberalismo e direitos sociais. Rio de Janeiro: Destaque, 1997. p. 37-52.

CHESNAIS, F. A mundialização do capital. São Paulo: Xamã, 1996.

COELHO, E. Uma esquerda para o capital: crise do marxismo e mudanças nos projetos políticos dos grupos dirigentes do PT (1979-1998). 2005. Tese (Doutorado em História) Programa de Pós-Graduação do Departamento de História, UFF, Niterói.

COUTINHO, C. N. A época neoliberal. Página Gramsci e o Brasil. Disponível em: <www.artnet.com.br>. Acesso em: out. 2008.

FIORI, J. L. O Consenso de Washington: palestra proferida no centro cultural banco do Brasil. Rio de Janeiro: FEBRAE, 1996. p. 1-2.

FORTI, V. Ética, crime e loucura: reflexões sobre a dimensão ética no trabalho profissional. Rio de Janeiro: Lumen Juris, 2009. Ética e economia: fundamentos para a discussão de direitos. In: FORTI, V.; 
GUERRA, Y. Ética e direitos: ensaios críticos. 2. ed. Rio de Janeiro: Lumen Juris, 2010. p. 130. (Coletânea Nova de Serviço Social).

GIANNOTTI, V. História das lutas dos trabalhadores no Brasil. Rio de Janeiro: Mauad X, 2007.

GUEDES, M. N. Anomalias da justiça do trabalho. 2007. Disponível em:

<www.terra.com.br> Acesso em: jul. 2007.

HARVEY, D. Condição pós-moderna. São Paulo: Loyola, 1993.

LEITE, J. C. P. A internacionalização da economia e a proteção do trabalhador. In: MACCALÓZ, M. S. et al. Globalização, neoliberalismo e direitos sociais. Rio de Janeiro: Destaque, 1997. p. 44-68.

MACCALÓZ, M. S. Globalização e flexibilização. In: MACCALÓZ, M. S. et al. Globalização, neoliberalismo e direitos sociais. Rio de Janeiro: Destaque, 1997. p. 1-26.

MARCONSIN, C. Cerco aos direitos trabalhistas e crise do movimento sindical no Brasil contemporâneo. 2009. Tese (Doutorado em Serviço Social) - Programa Pós-Graduação da Escola de Serviço Social da Universidade Federal do Rio de Janeiro, Rio de Janeiro.

MATTOS, M. B. Entregando a mão para não perder os dedos: o sindicalismo brasileiro e o desemprego. Revista Outubro, São Paulo, n. 1, p. 50-79, 1998.

NETTO, J. P. Crise do socialismo e ofensiva neoliberal. 3. ed. São Paulo, Cortez, 2001. v. 20. (Coleção Questões de Nossa Época).

NETTO, J. P.; BRAZ, M. Economia política: uma introdução crítica. 2. ed. São Paulo: Cortez, 2007. v.1. (Col. Biblioteca básica de serviço social).

ORGANIZAÇÃO INTERNACIONAL DO TRABALHO. Tendencias mundiales del empleo juvenil. 2012. Disponível em: <www.oit.org.br>. Acesso em: jun. 2012.

SADER, E. A nova toupeira: os caminhos da esquerda latino-americana. São Paulo: Boitempo, 2009.

TEIXEIRA, A. M. P. Previdência social no Brasil: da revolução passiva à contrarreforma. 2006. Tese (Doutorado em Serviço Social) - Programa de Pós-Graduação da Escola de Serviço Social da UFRJ, Rio de Janeiro.

TUMOLO, P. S. Da contestação à conformação: a formação sindical da CUT e a reestruturação produtiva. Campinas: UNICAMP, 2002. 